\title{
A Qualidade da Escola: Debatendo Princípios Rumo à Construção de uma Qualidade Socialmente Referenciada
}

\author{
The School Quality: Discussing Principles towards Building a \\ Socially Quality Referenced
}

\author{
Luana Costa Almeida*1 e Geraldo Antonio Betini ${ }^{2}$ \\ ${ }^{1}$ Universidade do Vale do Sapucaí y Universidade Estadual de Campinas \\ ${ }^{2}$ Universidade Estadual de Campinas
}

\begin{abstract}
Falar em qualidade nem sempre nos remete ao mesmo conceito ou objetivo de nossos interlocutores já que este termo é passível de diversas compreensões, as quais dependem das concepções e contextos teóricos e políticos aos quais se vinculam. Este artigo problematiza tanto o próprio conceito de qualidade, que não é único ou neutro, quanto a necessidade de abarcarmos os fatores internos e externos à escola se vislumbramos a construção da qualidade social. Dialogando com o conceito de educabilidade e com discussões atuais, em especial as voltadas à avaliação educacional, evidenciamos a necessidade de condições propícias ao trabalho escolar, assim como de que as escolas assumam efetivamente seu papel para a garantia da qualidade social.
\end{abstract}

Palavras-chave: Qualidade, Escola, Condições de escolarização.

Talking about school quality not always refers to the same concept or purpose as our interlocutors since this term is liable of different understandings, which rely on conceptions, and the theoretical and political contexts to which they are attached. This article discusses both the concept of school quality, which is not unique or neutral, as the necessity of encompassing internal and external factors to the school if the construction of social quality is pursued. Using the educability concept and current discussions, especially those on educational evaluation, we highlight the need for proper conditions at the school work, such as for schools effectively assuming their role to assure social quality.

Keywords: School quality, Sschool, Educability conditions.

O presente trabalho é fruto das reflexões dos autores, envolvidos como pesquisadores no Laboratório de Observação e Estudos Descritivos em projeto financiado pelo Programa Observatório da Educação da CAPES e, em especial, da tese de doutorado da primeira autora com financiamento da Fundação de Amparo à Pesquisa do Estado de São Paulo (Almeida, 2014).

*Contacto: luanaca@gmail.com

Recibido: $\quad 8$ de abril de 2016

issn: 1989-0397

www.rinace.net/riee/

$1^{\text {a }}$ Evaluación: 22 de junio de 2016

https://revistas.uam.es/riee 


\section{Introdução}

A realidade nos coloca à prova. Pensar os episódios vividos no cotidiano escolar é colocar em perspectiva a contradição vivida em nossas escolas. Reconhecer que nem sempre o desempenho escolar depende estritamente da ação da escola, e por isso ter a necessidade de relativizar a cobrança, não pode servir como respaldo para que esta instituição não assuma sua função de garantir uma escolarização de qualidade a todos os seus alunos. Mas afinal, o que seria essa qualidade?

Falar em qualidade não implica um entendimento a priori do que o termo significa, isso porque em dependência de seu ancoradouro político-ideológico ele pode se remeter a um modelo de educação ou a outro. É nesta perspectiva que procuramos, neste artigo, retomar o debate da questão da qualidade educacional, resgatando a discussão do tema na realidade brasileira, de forma a caminhar para a delimitação do que seria uma qualidade socialmente referenciada. Procuramos destacar, ainda, a contradição em que a escola se encontra, em especial as públicas, em que ao mesmo tempo que verdadeiramente necessita de determinadas condições para desenvolver seu trabalho, não pode as utilizar como desculpa para não exercer com profissionalismo e comprometimento seu papel social. Assim, a partir da retomada acerca do que significa, procuramos qualificar o termo qualidade, problematizando as potencialidades e limites da ação escolar.

Procuramos delimitar a qualidade que defendemos, de forma a permitir um posicionando crítico perante as políticas públicas que definem os rumos para seu alcance, especialmente aquelas voltadas à sua avaliação. Posicionamento que almeja, em última instância, a garantia da qualidade para todos os estudantes sem desconsiderar que ela não pode ser construída a priori, mas tomando a realidade vivenciada no dia a dia das escolas. Longe de se defender a falta de objetivos que contemplem conteúdos escolares, defende-se que para chegar a eles deve-se abarcar o sujeito concreto, em suas delimitações, limitações e, por conhecê-las, suas potencialidades.

\section{Contexto da discussão da qualidade}

Constantemente nos deparamos com discussões acerca da qualidade do ensino/educação, tanto em artigos de revistas, textos e debates promovidos pelas entidades da área, quanto dentro do discurso de profissionais da educação ou de sujeitos ligados à implementação de políticas públicas.

Já na década de 1990, no Brasil, Fernández Enguita (1999) problematizava a questão mencionando que se tratava da palavra da moda, se reportando ao discurso de organizações internacionais, manifestação de autoridades, centrais sindicais, associações de pais e professores, organização estudantil, empresários e especialistas da área, trazendo à tona, portanto, o movimento histórico a que estava ligada.

Todavia, embora associada a lutas históricas temos que ficar atentos ao que remete, já que, como o próprio Fernández Enguita (1999) alerta, o uso e predomínio de alguma expressão nunca é ocioso ou neutro. Algumas visões acerca da qualidade se mostram restritas e pouco vinculadas a debates mais profundos sobre seu significado, em especial nas políticas públicas, se atendo apenas a pressupostos técnicos que embora importantes, 
se distanciam, muitas vezes, do interesse dos sujeitos que concretamente a adotam (Moreira e Kramer, 2007).

Gentili (1999) desvela essa entrada da expressão qualidade em educação no cenário nacional brasileiro ao demonstrar que a qualidade requerida a partir dos anos de 1980, a qualidade total em educação, estava vinculada a uma lógica empresarial em que o que se buscava era uma eficiência pouco comprometida com um ideal de formação humano mais amplo, estando mais preocupada com a formação voltada aos interesses do mercado. O autor revela o abandono do ideário de democratização pelo da qualidade na perspectiva empresarial que não está, como possivelmente imaginado, voltado simplesmente ao próximo passo da democratização (houve acesso, agora lutaríamos pela qualidade), mas para uma lógica de eficiência em que se busca trazer para a escola a mesma lógica organizativa do mundo dos negócios.

Com essa ideia de qualidade, vimos surgir a implementação de testes padronizados, popularizados no Brasil a partir da década de 1990 com a criação do Sistema de Avaliação da Educação Básica -SAEB, os quais efetivam, além da medição em si, o ranqueamento das escolas na perspectiva de produzir certa concorrência entre os estabelecimentos, o que favoreceria, segundo a lógica de seus idealizadores, uma automelhoria das instituições a partir da quantificação de seus resultados, já que mobilizaria a busca por melhores posições nos rankings.

$\mathrm{Na}$ referida perspectiva, a avaliação em larga escala, como função do Estado, teria o papel de avaliar o ensino ofertado pelos estabelecimentos escolares, divulgando estes resultados para que a melhoria na qualidade ocorresse por iniciativa e ação das próprias escolas e redes, modelo estatal a que Barroso (2005) chama de "Estado avaliador".

Especialistas têm indicado que no Brasil, especialmente na década de 1990 quando foi criado o SAEB, o Estado, sob a hegemonia do neoliberalismo, sofreu mudanças profundas em sua organização e função contaminado pelos princípios da administração pública gerencial a qual, dentre outros aspectos, busca o controle estatal a partir dos resultados, sendo as políticas de avaliação uma grande ferramenta.

As políticas públicas implantadas neste contexto se pautaram em um Estado cujos "[...] modelos de governança e de regulação que se podem designar por pós-burocráticos organizam-se em torno de dois referenciais principais: o do 'Estado avaliador' e o do 'quase-mercado"” (Barroso, 2005, p. 737) em detrimento do Estado-Provedor que, como discutem alguns analistas, não significou necessariamente menos Estado e sim uma alteração na forma de regulação estatal e no seu papel perante o mercado (Barroso, 2005; Freitas, 2007).

Poderíamos pensar, então, que falar em qualidade estaria irreversivelmente associado apenas ao viés mercadológico, mas como nos alerta Vieira (1995), ao discutir o conceito de qualidade em educação abrangendo seu par dialético quantidade, este conceito não é estático, variando de acordo com circunstâncias temporais e espaciais o que nos coloca no campo da disputa pelo termo como bem pontua Gentili (1999):

[...] o significado da qualidade e, consequentemente, a definição dos instrumentos para avaliá-la, são espaços de poder e de conflito que não devem ser abandonados. Então, tratase de conquistar e impor um novo sentido aos critérios de qualidade empregados no campo educacional por (neo)conservadores e (neo)liberais. Devemos sustentar com decisão que não existe um critério universal de qualidade (ainda que os intelectuais reconvertidos assim o 
pretendam). Existem diversos critérios históricos que respondem a diversos critérios e intencionalidades políticas. Um é o que pretende impor os setores hegemônicos: o critério de qualidade como mecanismo de diferenciação e dualização social. Outro, o que devem conquistar os setores de esquerda: o da qualidade como fator indissoluvelmente unido a uma democratização radical da educação e a um fortalecimento progressivo da escola pública. (p. 172)

Reconhecer a disputa pelo termo é importante para ao falarmos em qualidade não acreditarmos que estamos utilizando um conceito novo ou de sentido único, em que todos os interlocutores possuiriam o mesmo entendimento acerca de seu significado e buscariam o mesmo objetivo ao anunciar sua luta, pois, como termo passível de diversas compreensões, depende inteiramente da análise e identificação das concepções e contextos teóricos e políticos aos quais o discurso está vinculado. A expressão "qualidade", portanto, é um termo que pode ser utilizado para interesses descomprometidos com a educação como direito social, como alerta Davok (2007):

A expressão "qualidade em educação", no marco dos sistemas educacionais, admite uma variedade de interpretações dependendo da concepção que se tenha sobre o que esses sistemas devem proporcionar à sociedade. Uma educação de qualidade pode significar tanto aquela que possibilita o domínio eficaz dos conteúdos previstos nos planos curriculares; como aquela que possibilita a aquisição de uma cultura científica ou literária; ou aquela que desenvolve a máxima capacidade técnica para servir ao sistema produtivo; ou, ainda, aquela que promove o espírito crítico e fortalece o compromisso para transformar a realidade social, por exemplo. (p. 506)

É importante destacar que, assim como afirma Fernández Enguita (1999), não está em questão abandonar a luta pela qualidade por ela ter sido tomada em grande parte pelo discurso daqueles que a vêm como mais um produto no mercado, mas disputar a qualificação do termo de forma a colocarmos em perspectiva a qualidade que queremos para nossas escolas, como direito de todos.

Tal análise marca a necessidade de termos clareza e buscarmos elucidar de que qualidade estamos falando, a serviço de quais objetivos, com que viés formativo, já que só a partir disso poderemos saber para onde e o quê olhar, sem nos deixarmos levar por um vazio conceitual que pouco contribuiria para a compreensão da realidade e a melhoria das condições educacionais vigentes, rumo a uma ação efetivamente promissora: "De facto, falar-se de "qualidade em" implica sabermos, perfeitamente, o que se entende por qualidade, pois o modo como entendemos esse conceito condiciona a forma de "medir" e, portanto, de "avaliar" a sua concretização no terreno" (Cabrito, 2009, p. 181).

Em busca de uma perspectiva para que se possa vislumbrar um ancoradouro para nossas reflexões, neste texto abordamos a discussão da qualidade na educação a partir da compreensão de que ela é um conceito construído, não sendo possível tomá-lo como absoluto, sendo necessário que se respeite a característica plural e mutável de sua produção (Franco, 1992), a qual tem objetivos em nível macro a serem alcançados, mas não perde de vista sua natureza transitória e dependente dos sujeitos envolvidos, como nos indica Bondioli (2004).

Os referidos objetivos no nível macro são os objetivos sociais para a educação a serem definidos a partir de políticas públicas cuja ação tenha como perspectiva o modelo de sociedade e homem que deseja formar, o qual gera uma determinada qualidade geral que deve ser atingida para além do que é essencial ao contexto escolar específico.

Com as contradições (problemas ou situações incomodativas) definidos e priorizados (em função do estudante, em primeiro lugar) e com as marcas ou indicadores de 
acompanhamento definidos, aparece a possibilidade de negociarmos novas marcas a serem obtidas, ou compromissos e demandas. (Freitas, 2006, p. 6)

Assim sendo, assumimos que definir qualidade implica observar as condições de produção, reconhecendo sua característica variável, a partir da noção de negociação (Bondioli, 2004; Freitas, 2005), em que os fatores que a definem e a ela são importantes são construídos nas unidades escolares tendo em vista tanto os objetivos macro e parâmetros gerais, nacionais e da rede, quanto as necessidades e estruturas locais, estando em constante negociação e avaliação para que determinada qualidade seja definida e alcançada considerando os diversos aspectos do processo. Estes aspectos, tanto internos quanto externos à instituição, devem ser abarcados no movimento de busca pela qualidade, a qual passamos a adjetivar, para definir, como socialmente referenciada: a qualidade social.

\section{A qualidade social em educação}

Entendemos que para definir qual a qualidade necessária para a educação é fundamental olharmos a escola como uma instituição social complexa que se propõe a alcançar objetivos específicos de educação formal, tendo como referência e princípio normativo e valorativo a sociedade em que está inserida (Chauí, 2003). Esta, como uma instituição social voltada para a educação, tem como objetivo a apropriação pelo aluno do conhecimento acumulado pela humanidade, o desenvolvimento de habilidades cada vez mais complexas e a formação de valores para enfrentar e superar conflitos e problemas de ordem pessoal e social de maneira crítica.

Os objetivos da escola, como instituição social, não são definidos apenas no âmbito da particularidade, ainda que tenha nele importante espaço de negociação e apropriação, são definidos no todo da sociedade em vias do que se pretende construir em seu conjunto, daí o caráter político e ideológico da educação. Partimos, portanto, da premissa de que a educação é uma "prática social e um ato político" (Silva, 2009, p. 216) e que sendo assim, devemos diferenciar aquela que se pratica nas empresas, a qualidade total, daquela que almejamos para a escola pública, a qualidade social.

Seguindo a lógica do mercado, a questão da preparação para o trabalho, a formação técnica, é vista como o mais importante objetivo da escola (Rodrigues, 1984), aspecto que nos preocupa já que nesta perspectiva o trabalho é visto de forma restrita e subordinada ao interesse produtivista do empresariado. $\mathrm{Na}$ qualidade socialmente referenciada, por outro lado, vislumbra-se a formação para o trabalho, mas não se restringe a ela, passando a priorizar outros campos constituintes da formação humana. Por exemplo, no campo da cultura os estudantes teriam a oportunidade de construir uma visão de mundo mais ampla; no campo da preparação política uma participação mais efetiva na sociedade civil; no campo do trabalho, preparação para uma profissão, condições de inserção na vida social etc.

Quando focamos apenas resultados, estamos enfatizando a qualidade total. Por outro lado, quando buscamos a formação do aluno, que vai além da preparação técnica, estamos falando da qualidade socialmente referenciada, aquela que "tem profundos e diferenciados sentidos filosóficos, sociais e políticos” (Dias Sobrinho, 1995, p. 34). 
A qualidade praticada pela escola tem de se diferenciar radicalmente da qualidade mercantil. Deve ser um direito de todos os alunos e não o privilégio de alguns. A qualidade socialmente referenciada é diametralmente oposta a uma visão mercantil e utilitarista, necessárias à perspectiva assumida pelas empresas, porém incompatíveis com o campo da educação que visa uma formação humana mais ampla:

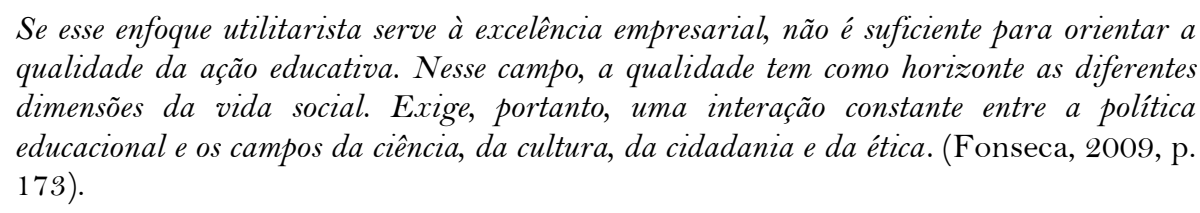
qualidade da ação educativa. Nesse campo, a qualidade tem como horizonte as diferentes dimensões da vida social. Exige, portanto, uma interação constante entre a política educacional e os campos da ciência, da cultura, da cidadania e da ética. (Fonseca, 2009, p. 173).

Embora a qualidade na escola pública brasileira comece na quantidade de alunos que a frequentam, um dos pilares da democratização do ensino, sendo a presença das crianças pobres na escola um avanço histórico, necessitamos continuar a luta já que a permanência e a qualidade, outros pilares da democratização, ainda não correspondem ao desejado e necessário em nosso país. A contradição subjacente ao fato tem que entrar para o embate teórico e político da qualidade da educação, como uma forma de luta.

A qualidade social é um objetivo necessário às escolas públicas para garantir a real democratização da educação, o qual deve abranger o propósito de melhorar as ações educativas, conservando aquelas que hoje apresentam bons resultados e mudando ou redirecionando as não adequadas à melhoria dos patamares de formação dos estudantes. Esta qualidade deve ser meta comum a todos os alunos, sem distinção, preservando os direitos de todos, sem que se substitua a problemática da igualdade, pela da igualdade de oportunidades (Fernández Enguita, 1999), a qual, muitas vezes, naturaliza as diferenças nos resultados justificando-as pelas aptidões individuais (dons).

Para alcançar esta qualidade, todavia, é necessário que percebamos que este conceito está diretamente relacionado ao conceito de avaliação, já que quando avaliamos conseguimos redirecionar ações e manter aquelas adequadas aos objetivos propostos, analisando tanto os processos, quanto os resultados em si. Portanto, avaliar a instituição escolar é necessário para analisar a realidade de nossas instituições em vias de melhorar a qualidade de sua ação.
Avaliação e qualidade apresentam-se, pois, como dois segmentos que se completam de modo indissociável. Há necessidade de se avaliar para se desenvolver a qualidade e há necessidade de se avaliar e inovar a própria avaliação. Isolar, aqui, pode significar "rodar em falso", visto que o risco de não se chegar a lugar algum é muito grande. (Balzan, 1995, p. 119)

As avaliações de larga escala empreendidas pelos órgãos governamentais, federais, estaduais e municipais, têm a sua importância, porém o seu peso na análise educacional deve ser relativo. A escola deve compor com essas avaliações a sua própria, a qual não deve se restringir apenas ao desempenho dos alunos em provas cognitivas ou de habilidades, mas também abranger todo o processo e estrutura escolar, criando caminhos próprios de avaliação institucional, envolvendo os alunos e suas famílias.

\footnotetext{
É preciso, pois, criarem-se mecanismos institucionais que avaliem, e avaliem bem, não apenas o desempenho do aluno, mas todo o processo escolar, tendo também os pais e os estudantes como avaliadores, pois eles são os usuários da escola e seus interesses é que devem ser levados em conta na identificação dos problemas e no levantamento das soluções. (Paro, 1997, p. 94)
}

Acreditando que avaliação e qualidade são conceitos imbricados, que isolar um do outro não contribui para que a escola atinja os seus objetivos de oferecer uma educação de 
qualidade a todos, é necessário que a instituição encontre mecanismos que possam ajudála a avaliar seu desempenho, se está ou não atingindo seus objetivos. Para tanto, podemos lançar mão de indicadores de qualidade, cujos objetivos são estabelecer marcas de chegada e que se constituem em referência de ações para toda a escola, representando dados de qualidade que podem ser utilizados na avaliação do seu desempenho.

\section{[...] Assim, a avaliação da qualidade em educação deve recorrer a uma bateria de indicadores de natureza quantitativa, mas também qualitativa, que pode, aliás, ser diferente de escola para escola. Quanto maior for o número daqueles indicadores de contexto, mais bem espelhada será a realidade que se pretende avaliar. (Cabrito, 2009, p. 197)}

A avaliação da qualidade da educação escolar não deve servir para comparação entre escolas como presenciamos hoje por meio das avaliações de larga escala (rankings), já que essa comparação serve apenas para promover discriminações, exclusões sociais e aprofundamento das desigualdades, estando longe de servir à melhoria da escola pública. A avaliação da qualidade da escola só tem sentido se servir para que direcione, ou redirecione, os percursos, melhorando os processos e resultados a fim da promoção de uma educação de qualidade social.

A qualidade social, nesta perspectiva, “[ [...] não se restringe a fórmulas matemáticas, tampouco a resultados estabelecidos a priori e a medidas lineares descontextualizadas" (Silva, 2009, p. 223, grifo do autor), mas sim a uma busca pela formação ampla dos sujeitos, a qual deve atingir variados aspectos do ser social na perspectiva de uma formação omnilateral (Frigotto, 1996) não se restringindo ao que pode ser avaliado pelos testes em larga escala e que só se consolida a partir do trabalho integrado entre os diferentes atores envolvidos (escola, comunidade, Estado) na intenção de construir uma sociedade menos excludente e desigual.

A meta seria proporcionar a todas e cada uma das crianças os meios objetivos e subjetivos para se tornarem cidadãos críticos e comprometidos com seu tempo e com a construção de uma sociedade mais justa e igualitária. Esta, todavia, não pode ser alcançada senão a partir da compreensão dos vários condicionantes a que está exposta. Como bem esclarece Silva (2009):

É preciso levar em conta que, às questões que envolvem domínio de conhecimentos, códigos, linguagens e raciocínio lógico, próprios da natureza da formação escolar, somam-se outras, como vida familiar, ambiência cultural, condições de transporte, de alimentação, acessibilidade a livros, hábitos de leitura, acesso a equipamentos tecnológicos, que, juntos, constituem a amplitude da formação [...]. (p. 220)

Assim, a busca pela qualidade socialmente referenciada vislumbra tanto os fatores internos à escola (estrutura, organização técnica e pedagógica, formação docente etc.), quanto os externos (estrutura e organização do entorno social, condições objetivas de subsistência das crianças atendidas, participação da família na vida escolar dos filhos etc.) compondo um todo que permita olhar para o processo de escolarização inserido no processo mais amplo de vida, sem que se vislumbre a escola como uma instituição isolada do meio social no qual está inserida.

\section{Qualidade social: Condicionantes em debate}

Observando o aumento gradativo da utilização dos índices gerados a partir das avaliações em larga escala como retrato da realidade educacional e representativos da 
qualidade escolar das instituições, a partir dos quais se elabora políticas públicas voltadas à regulação dos sistemas de ensino, vemos crescer no Brasil as ações em que se responsabiliza unicamente às escolas e seus profissionais pelos resultados alcançados (accountability).

Como já discutido por Almeida; Dalben e Freitas (2013), especificamente discutindo o Índice de Desenvolvimento da Educação Básica - IDEB, no Brasil há uma divulgação dos resultados das avaliações educacionais em larga escala para a população de forma em que as unidades escolares aparecem como responsáveis pelo seu desempenho sem qualquer vinculação à relação deste com seu entorno social ou com as políticas públicas às quais está, direta ou indiretamente, submetida, gerando certo isolamento da escola e, em consequência, a ideia de que ela e seus profissionais seriam os culpados pelos resultados obtidos.

Esta responsabilização verticalizada induziria, de forma equivocada, a ideia de que o entorno social e as políticas públicas pouco interfeririam sobre os resultados das avaliações, o que gera, em última instância, a desresponsabilização de forma branda do sistema educativo e social mais amplo sobre tais resultados. Aspecto perigoso por fomentar o movimento de "[...] responsabilização unidirecional da escola e de seus profissionais sem que a eles sejam dadas as condições objetivas de melhoria da qualidade do ensino ofertado à população." (Almeida, Dalben, Freitas, 2013, p. 1169).

A partir da percepção de que muitos dos problemas educativos são na verdade problemas sociais (Navarro, 2004, p. 29) o conceito de educabilidade nos ajuda a problematizar esta situação à medida que coloca em perspectiva a observação de que a escola não pode, isoladamente, resolver todas as questões que impedem que seus alunos obtenham alto nível de proficiência nas habilidades acadêmicas. Ela deve ser analisada em sua realidade e condições objetivas de desenvolvimento do trabalho educativo.

Saber dessa realidade evidencia, mais fortemente, a necessidade de compreendermos que a escola tem grandes possibilidades de ação, mas também severos limites. As consequências para a ação dos profissionais da escola são imediatas já que devem ter, como horizonte, os objetivos educacionais a serem alcançados, sem, todavia, desconsiderar as condições concretas de vida de seus alunos. Aspecto que implica o que poderíamos chamar de duplo desafio da escola: compreender que não pode tudo perante as condições de vida de seus alunos, mas também que não pode se utilizar dessa realidade como desculpa para o desenvolvimento de um trabalho aquém ao que poderia para garantir uma melhor formação de seus estudantes.

Adentrar esta contradição nos coloca na situação de uma dupla tarefa: lutar pela melhoria das condições para o desenvolvimento do trabalho da escola e lutar para que esta instituição assuma com responsabilidade o seu papel social. Tarefa que, ao assumirmos a busca da qualidade socialmente referenciada, exige um olhar mais sensível aos fatores que a envolvem e determinam, pois como nos indicam Moreira e Kramer (2007):

A promoção de uma educação de qualidade depende de mudanças profundas na sociedade, nos sistemas educacionais e na escola. Nesses dois últimos, exigem-se: condiç̃̃es adequadas ao trabalho pedagógico; conhecimentos e habilidades relevantes; estratégias e tecnologias que favoreçam o ensinar e o aprender; procedimentos de avaliação que subsidiem o planejamento e o aperfeiçoamento das atividades pedagógicas; formas democráticas de gestão da escola; colaboração de diferentes indivíduos e grupos; diálogo com experiências não-formais de 
educação; docentes bem formados (que reconheçam o potencial do aluno e que concebam a educação como um direito e um bem social). (p. 1046)

Cada instituição deve se conhecer e acordar suas ações de forma a atender a população, garantindo tanto o âmbito da instrução, quanto o da formação geral, ainda que isso signifique a tensão entre " [ [...] a exigência do sistema escolar por melhores resultados que deveria obter em provas nacionais e a demanda de pertinência que cotidianamente lhe levanta o bairro e a situação de vida de seus estudantes" (Navarro, 2004, p.84, tradução nossa). Aspecto que remete à impossibilidade de se pensar em ações únicas para as diferentes instituições já que, como esclarece López (2009, tradução nossa):

[...] para garantir igualdade de resultado, a forma de ação de um estabelecimento que se encontra em um bairro de classe média urbana não deve ser a mesma que outro que se encontra em bairros rurais ou em bairros periféricos das grandes cidades. (p. 21)

Dentro do debate acerca dos fatores necessários à busca da qualidade socialmente referenciada estão tanto aqueles voltados às variáveis intra-escolares (trabalho pedagógico, tecnologias de ensino, avaliação, planejamento, formação docente, gestão etc.), quanto às extra-escolares (comunidade, nível socioeconômico, família, acesso a serviços, condições objetivas de subsistência etc.), considerando, como explicitam Bello e Villarán (2009, tradução nossa), que o trabalho da escola envolve seus projetos, mas em relação à população que atende:

A pertinência da educação está fortemente vinculada à relação que estabelece a escola com a
comunidade e o contexto onde está localizada, assim como sua capacidade de colocar à
disposição da comunidade um conjunto de serviços para apoiar seu desenvolvimento e para
promover sua participação nas ações e nos projetos que a escola promove. [...]. (p. 156)

Pensar na possibilidade de um estabelecimento alcançar a qualidade social é, sem dúvida, pensar nas condições de escolarização das crianças, questionando a possibilidade concreta da escola alcançar altos níveis de desempenho sem que se problematize a realidade da população atendida, ou seja, sem que se adicione à equação as condições socioeconômicas e culturais e de subsistência em que as crianças chegam e frequentam à escola, essenciais para que o projeto escolar que temos em nossa sociedade, avaliado em parte pelos testes padronizados, logre êxito.

Como aponta López (2005, p. 132, tradução nossa) parecem estar cada vez mais nítidas "as limitações dos sistemas educativos frente a cenários tão devastados em que seus alunos não contam com condições mínimas que lhes permitam participar do processo educativo". Para o autor, devemos estar atentos à educabilidade dos alunos, a qual é definida como a capacidade das crianças frequentarem com êxito a escola aproveitando a estrutura educacional disponível.

Nas palavras de Navarro (2004, p. 30, tradução nossa) a educabilidade diz respeito a interrogar a sociedade sobre sua "responsabilidade política na provisão de condições, recursos e oportunidades para que os alunos aprendam e os professores ensinem, especialmente em contextos de pobreza".

Em nossa perspectiva, a educabilidade se relaciona ao que chamamos de condições de escolarização à medida que se configura como a delimitação das condições necessárias para que a escola desenvolva seu trabalho, sem implicar um descompromisso da instituição com aqueles que não se adequam a certo padrão. Essa noção recoloca no debate os limites da escola, reafirmando que existem condições necessárias para que 
crianças e adolescentes percorram de forma mais proveitosa o processo educacional, o que não implica a impossibilidade de fazer algo por aqueles que não as têm. Ou seja, não se quer dizer que sem determinadas condições pré-estabelecidas a escola não vá fazer nada por seus alunos, mas, sim, que existe uma tensão entre os recursos que as crianças têm, os que a escola espera delas (ou exige) e as condições concretas que esta instituição tem e mobiliza para trabalhar com a realidade da população que atende, nem sempre uma equação de resultado positivo.

Não se trata, porém, de esperar um aluno ideal, mas de almejar que a população atendida tenha acesso aos direitos básicos previstos na Costituição brasileira de 1988 em seu artigo sexto, o qual prevê que são direitos sociais de todos os brasileiros "a educação, a saúde, a alimentação, o trabalho, a moradia, o lazer, a segurança, a previdência social, a proteção à maternidade e à infância, a assistência aos desamparados [...]" (Brasil, 1988).

Vale ressaltar, todavia, que, como destaca Navarro (2004) em relação à noção de educabilidade, as condições de escolarização são uma dimensão relacional, situacional e aberta e por isso não cabe rotular alguém como educável ou não educável, já que esta é uma condição passível de ações sociais e que nos serve como conceito analítico de uma situação a ser enfrentada pela escola e pelas políticas públicas sociais de forma mais geral, mas não como ferramenta de separação de grupos (os educáveis e os não educáveis), sendo a escola responsável por propor e desenvolver seu trabalho de forma a atender da melhor maneira possível a população que a frequenta, possuindo ou não as condições propícias de escolarização, assumindo seu importante papel na efetivação da qualidade socialmente referenciada.

Reconhecer a existência de condições de escolarização não significa, portanto, voltar à ideia de uma determinação de sucesso ou fracasso escolar a partir da constatação da realidade vivida pelos alunos, muito comum no Brasil durante as décadas de 1960 e 1970, permitindo, hoje, a desculpa pelo trabalho inadequado de muitas escolas em relação a seus estudantes. É, por outro lado, entender que a escola tem responsabilidade compartilhada no desempenho de seus alunos, e que para lograr êxito necessita de condições para o trabalho, as quais devem ser demandadas horizontalmente (dentro da própria instituição e de sua rede) e verticalmente (ao Estado), tanto no âmbito do trabalho pedagógico, propriamente dito, quanto no âmbito das condições objetivas de vida dos estudantes e de suas famílias. Aspecto que depende de forma substancial de uma ação conjunta das políticas sociais.

Internamente, a escola deve ter sempre a preocupação de melhorar o nível de qualidade da educação ofertada aos seus alunos, não só em termos de resultados finais, mas também em relação aos processos escolares, sejam eles pedagógicos ou administrativos.

Na dimensão pedagógica entendemos que a procura da qualidade da escola concentra-se no projeto político pedagógico; currículo; formação continuada dos professores; avaliação, planejamento e execução do processo de ensino-aprendizagem; organização do trabalho didático. Na dimensão administrativa temos tanto a administração de tarefas em que os pontos de atenção da direção voltam-se para a administração burocrática; planejamento; decisão; organização/coordenação; delegação; suporte no trabalho; avaliação de resultados, quanto a administração de pessoas em que a atenção se volta para o desenvolvimento dos profissionais da escola; motivação; reconhecimento; consideração; comunicação e trabalho em equipe (Betini, 2009). 
Assim, resumidamente, concordamos com Silva (2009) quando afirma:

No interior da escola, outros elementos sinalizam a qualidade social da educação, entre eles, a organização do trabalho pedagógico e gestão da escola; os projetos escolares; as formas de interlocução da escola com as famílias; o ambiente saudável; a política de inclusão efetiva; o respeito às diferenças e o diálogo como premissa básica; o trabalho colaborativo e as práticas efetivas de funcionamento dos colegiados e/ou conselhos escolares. (p. 224)

A articulação dos objetivos pedagógicos (formação integral do aluno) com os objetivos administrativos (tarefas e pessoas) em uma ação conjunta da escola com a participação de todo o seu coletivo, por meio do Projeto Político Pedagógico ou de um plano de ação específico, pode indicar possíveis caminhos a serem seguidos na busca e alcance da qualidade socialmente referenciada.

Garantir a qualidade educacional passa, nesta perspectiva, por agir tanto nas escolas enquanto instituições educativas (em sua ação), quanto nas condições objetivas de vida das crianças (sua subsistência e desenvolvimento sociocultural) sendo, por consequência, agir em suas condições de escolarização.

Pensar nos condicionantes da qualidade socialmente referenciada é, assim, pensar tanto nos fatores internos à instituição, quanto nos externos a ela (tabla 1), tendo em vista que a construção da qualidade social em nossas escolas deve ser um processo de responsabilização partilhada em que todos os atores devem assumir sua responsabilidade no processo, demonstrando compromisso com a formação de nossas crianças e adolescentes.

Tabela 1. Fatores necessários à construção da qualidade educacional

Projeto político-pedagógico desenvolvido para favorecer o trabalho da escola; currículo bem Condições pedagógicas construído; formação continuada dos professores; avaliação, planejamento e execução do processo de ensino-aprendizagem; organização adequada do trabalho didático etc.

FATORES Administração de tarefas (administração

INTERNOS burocrática; planejamento; decisão; burocrática; planejamento; decisão;
organização/coordenação; delegação; suporte no Condições administrativas trabalho avaliação de resultados) e administração de pessoas (desenvolvimento dos profissionais da escola; motivação; reconhecimento; consideração; comunicação e trabalho em equipe)

\begin{tabular}{lll}
\hline & Condições de subsistência & Moradia, alimentação, saúde \\
\cline { 2 - 4 } Condições socioeconômicas e & $\begin{array}{l}\text { Acesso a bens e recursos (computador, livros, } \\
\text { televisão, passeios, cinema etc.) }\end{array}$ \\
\cline { 2 - 4 } EATORES & Condurais & $\begin{array}{l}\text { Disponibilidade de estrutura urbana e acesso aos } \\
\text { serviços públicos (saneamento básico, transporte } \\
\text { público, educação pública etc.) }\end{array}$ \\
\cline { 2 - 4 } & Condições subjetivas & $\begin{array}{l}\text { Acompanhamento por adulto responsável; } \\
\text { amparo emocional etc. }\end{array}$ \\
\hline
\end{tabular}

Fonte: Organização dos autores.

Embora o quadro anterior não tenha a pretensão de esgotar os diferentes fatores associados às necessidades para a construção e exame da qualidade socialmente referenciada, nem abranger todas as possibilidades para a análise de cada escola, 
constitui-se como referência para a observação de diferentes condicionantes da qualidade social, os quais existem e agem de forma particular nas diferentes instituições em dependência de sua realidade, devendo ser apropriados e (re)dimensionados na avaliação de cada instituição de forma não apenas a fortalecer seu autoconhecimento, como de fomentar a modificação de suas ações e percursos.

Acreditamos que a avaliação formativa da escola seja peça fundamental para as mudanças necessárias nesta instituição, já que é a partir desse conhecimento que seus limites e potencialidades vão sendo clarificados e, dessa forma, as possibilidades de ação para reforço das potencialidades e melhoramento dos limites podem ser orquestradas, num movimento de constante negociação entre os atores envolvidos acerca de suas prioridades, mas sempre em vias de atingir o objetivo da qualidade socialmente referenciada da escola que, em primeiro lugar, tem a criança como foco.

\section{Algumas considerações}

Falar em qualidade requer que façamos o exercício de buscar o ancoradouro ideológico da questão e os fatores que influenciam sua conquista. Assumimos como norte a qualidade socialmente referenciada e não tivemos a pretensão de esgotar a discussão, mas buscar elencar, a partir de nossas pesquisas e discussões, alguns aspectos que acreditamos importantes para sua análise e construção.

Embora a lógica dos negócios, nos últimos anos, tenha pautado a questão da qualidade da educação brasileira, reforçada por políticas públicas implementadas, em especial poderíamos citar as políticas de avaliação em larga escala, observamos que o tema vem sendo motivo de embate. Há certa mobilização das proposições sociais em contraposição à lógica empresarial que busca imprimir o caráter mercadológico na educação, visando as pessoas apenas como produtores e consumidores postos no mercado.

Defendemos o abandono da lógica empresarial à medida que, como vimos discutindo, a qualidade educacional deve transcender a técnica; ela deve abranger aspectos sociopolíticos e filosóficos, dando à educação um sentido fundamentalmente humanístico e não apenas utilitário. Se a qualidade total faz sentido para o mundo dos negócios, ela deixa a desejar quando se trata do campo educacional, já que restringe a formação do indivíduo, visando o trabalho necessário ao mercado, sem sequer se comprometer com uma visão mais ampla do mundo do trabalho e em detrimento de uma atuação social e política no meio em que vive.

Um aspecto importante a se considerar é como as políticas públicas têm conduzido o processo de avaliação da qualidade da educação brasileira, já que embora avaliar a educação seja fundamental para se ter o panorama de sua realidade e contexto, pois será por meio dela que a escola poderá melhorar os seus processos e resultados, esta não pode se restringir apenas a medidas ou indicadores quantitativos, como vem sendo praticado no Brasil. Não somos contra a avaliação da educação pelos poderes públicos, porém advogamos um sistema que contemple também as avaliações internas de cada escola a qual inclua, além dos indicadores normalmente adotados, indicadores qualitativos que poderão abarcar a especificidade de cada contexto escolar e das várias dimensões formativas necessárias quando pensamos na formação do humano.

É importante que o poder público forneça as condições objetivas para que a escola possa trabalhar, assim como que a instituição de ensino aprimore as suas ações, vislumbrando 
altos níveis de qualidade social. Defendemos que a negociação é um aspecto essencial na busca por essa qualidade e que esta seja feita não apenas internamente à instituição, mas em cooperação entre Estado e escola, de forma a construir-se como responsabilidade partilhada pela qualidade oferecida à população atendida.

Faz-se necessário, em vias da efetivação da responsabilização partilhada, que tanto o Estado garanta os direitos sociais das crianças já previstos em nossa Constituição Federal, quanto que as escolas assumam seu papel no trabalho com os alunos reais, não transferindo toda a responsabilidade da falta ou do pouco aprendizado destes às condições socioeconômicas e culturais de origem, tendo projetos e processos pedagógicos que façam frente às condições adversas, sempre objetivando uma aprendizagem efetiva.

A qualidade social que defendemos para a escola pública brasileira constitui-se, então, em um conjunto de dimensões pedagógicas, culturais, administrativas, socioeconômicas e culturais que precisam ser levadas em consideração pelas políticas públicas educacionais com o objetivo de transformar a educação, de modo especial aquela ofertada às camadas menos favorecidas, em algo que as habilite a ter uma vida social, política, produtiva e criativa mais efetiva.

Falar em qualidade socialmente referenciada requer que façamos o exercício de buscar os fatores que a influenciam, sem perder de vista que a complexidade da realidade requer uma análise ampla e capaz de observar os movimentos de contradição do fenômeno analisado para o qual a perspectiva de processo, e não simplesmente resultado, é essencial.

\section{Referencias}

Almeida, L. C. (2014). Relação entre o desempenho e o entorno social em escolas municipais de Campinas: A voz dos sujeitos. (Tese de Doutorado, Universidade Estadual de Campinas, Campinas-SP, 326f).

Almeida, L. C., Dalben, A. e Freitas, L. C. (2013). O IDEB: Limites e ilusões de uma política educacional. Educação \& Sociedade, 34(125), 1153-1174. doi:10.1590/so10173302013000400008

Balzan, N. C. (1995). A voz do estudante - Sua contribuição para a deflagração de um processo de avaliação institucional. Em N. C. Balzan e J. Dias Sobrinho (Eds.), Avaliação institucional: Teoria e experiências (pp. 115-147). São Paulo: Cortez.

Barroso, J. (2005). O Estado, a educação e a regulação das políticas públicas. Educação $\Xi^{\circ}$ Sociedade, 26(92), 725-751. doi:10.1590/s0101-73302005000300002

Bello, M. e Villarán, V. (2009). Las relaciones de la escuela con la familia y la comunidad, en el camino hacia la equidad. Em N. López (Ed.), De relaciones, actores y territorios: Hacia nuevas políticas para la educación en América Latina (pp. 115-170). Buenos Aires: IIPE-UNESCO.

Betini, G. A. (2009). Indicadores para um plano de ação em avaliação institucional participativa: Uma possibilidade. Em M. R. L. Sordi e E. S. Souza (Ed.), A avaliação como instância mediadora da qualidade da escola pública (pp. 117-132). Campinas: Millennium Editora.

Bondioli, A. (Ed.). (2004). O projeto pedagógico da creche e sua avaliação: A qualidade negociada. Campinas: Autores Associados. 
Brasil. (1988). Constituição da República Federativa do Brasil de 1988. Disponível em http://www.planalto.gov.br/ccivil_o3/constituicao/constituicao.htm

Cabrito, B. G. (2009). Avaliar a qualidade em educação: Avaliar o quê? Avaliar como? Avaliar para quê? Cadernos Cedes, 29(78), 178-200. doi:10.1590/s0101-32622009000200003

Chaui, M. (2003). A universidade pública sob nova perspectiva. Revista Brasileira de Educação, (24), 5-15. doi:10.1590/s1413-24782003000300002

Davok, D. F. (2007). Qualidade em Educação. Avaliação, 3(12), 505-513. Disponível em http://www.scielo.br/pdf/aval/v12n3/a07v12n3.pdf

Dias Sobrinho, J. (1995). Universidade: Processos de socialização e processos pedagógicos. Em J. Dias Sobrinho e N. C. Balzan (Eds.), Avaliação institucional: Teoria e experiências (pp. 15-35). São Paulo: Cortez Editora.

Fernández Enguita, M. (1999). O discurso da qualidade e a qualidade do discurso. En P. Gentili e T. T. Silva (Eds.). Neoliberalismo, Qualidade Total e Educação (4 ${ }^{\mathrm{a}}$ ed., pp. 93-110). Petrópolis/RJ: Vozes.

Fonseca, M. (2009). Políticas públicas para a qualidade da educação brasileira: Entre o utilitarismo econômico e a responsabilidade social. Gestão institucional e qualidade social da educação. Caderno Cedes, 29(78), 153-177. doi:1590/s0101-32622009000200002

Franco, M. L. P. B. (1992). Qualidade do ensino: Velho tema, novo enfoque. Cadernos de Pesquisa, $83,64-70$

Freitas, D. N. (2007). A avaliação da educação básica no Brasil: Dimensão normativa, pedagógica e educativa. Campinas: Autores Associados.

Freitas, L. C. (2006). Níveis de avaliação/indicadores. Apresentação de trabalho feita aos pesquisadores do LOED. Campinas: Universidade Estadual de Campinas, Faculdade de Educação.

Freitas, L. C. (2005). Qualidade negociada: Avaliação e contra-regulação na escola pública. Educação Ẽ Sociedade, 26(92), 911-933. doi:10.1590/s0101-73302007000300018

Frigotto, G. (1996). A formação e a profissionalização do educador: Novos desafios. Em T. T. Silva e P. Gentili (Orgs.), Escola S.A.: Quem ganha e quem perde no mercado educacional do neoliberalismo (pp. 75-85). Brasília: CNTE.

Gentili, P. (1999). O discurso da "qualidade" como nova retórica conservadora no campo educacional. Em P. Gentili e T. T. Silva (Ed.), Neoliberalismo, qualidade total e educação (pp. 111-117). Petrópolis: Vozes.

López, N. (2005). Educación y equidad. Algunos aportes desde la noción de educabilidad. Em I. Hernaiz, E. S. Chávez e V. Villarán (Ed.), Educación y desarrollo local: Tensiones y perspectivas. Reflexiones sobre experiencias en la región andina (pp. 131-162). Buenos Aires: IIPE-UNESCO.

López, N. (Ed.). (2009). De relaciones, actores y territorios: Hacia nuevas políticas para la educación en América Latina. Buenos Aires: IIPE-UNESCO.

Moreira, A. F. B. e Kramer, S. (2007). Contemporaneidade, educação e tecnologia. Educação छ̊ Sociedade, 28(100), 1037-1057. doi:10.1590/s0101-73302007000300019

Navarro, L. N. (2004). La escuela y las condiciones sociales para aprender y enseñar: Equidad social y educación en sectores de pobreza urbana. Buenos Aires: IIPE-UNESCO.

Paro, V. H. (1997). Gestão democrática da escola pública. São Paulo: Editora Ática.

Rodrigues, N. (1984). Função da escola de $1^{\circ}$. Grau numa sociedade democrática. Revista da Associação Nacional de Educação, 4(8), 17-22. 
Silva, M. A. (2009). Qualidade social da educação pública: Algumas aproximações. Cadernos Cedes, 29(78), 216-226. doi:10.1590/s0101-32622009000200005

Vieira, S. L. (1995). Concepções de qualidade e educação superior. Pró-posições, 6(1), 105-1 14.

\section{Breve CV de los autores}

\section{Luana Costa Almeida}

Doutora em Educação na área de Ensino e Práticas Culturais pela Universidade Estadual de Campinas-Unicamp (2014), com período de estágio na Universidade Autônoma de Barcelona-Espanha. Mestre em Educação na área de Ensino, Avaliação e Formação de Professores (2008) e graduada em Pedagogia (2004), ambos pela Unicamp. Fez pós-doutorado no Centro de Estudos da Metrópole-CEM/Cebrap (2014/2015). Atualmente atua como Professora do Mestrado em Educação da Universidade do Vale do Sapucaí-Univás e como Professora Doutora em RTP na Faculdade de EducaçãoUnicamp. É pesquisadora colaboradora no Laboratório de Observação e Estudos Descritivos-LOED-Unicamp, em projeto financiado pelo Observatório da EducaçãoCAPES e participa do Comitê Editorial da revista Educação \& Sociedade.

\section{Geraldo Antonio Betini}

Doutor na área de Ensino, Avaliação e Formação de Professores (2009) pela Universidade Estadual de Campinas, mestre em Educação (2002) pela Universidade Estadual de Campinas (UNICAMP) e graduado em Pedagogia pela Pontifícia Universidade Católica de Campinas (1969). Atuou como pesquisador colaborador no Laboratório de Observação e Estudos Descritivos (LOED) - Faculdade de Educação/ UNICAMP. Tem experiência em Educação e Recursos humanos, atuando principalmente nos seguintes temas: Avaliação da aprendizagem e institucional. Gestão educacional, Relação escola-entorno. 